\title{
An interdisciplinary perspective on social and physical determinants of seismic risk
}

\author{
K.-H. E. Lin ${ }^{1,2}$, Y.-C. Chang ${ }^{3}$, G.-Y. Liu ${ }^{4}$, C.-H. Chan ${ }^{5}$, T.-H. Lin ${ }^{6}$, and C.-H. Yeh ${ }^{4}$ \\ ${ }^{1}$ George Perkins Marsh Institute, Clark University, 950 Main Street, Worcester, MA 01610, USA \\ ${ }^{2}$ Research Center for Environmental Changes, Academia Sinica, 128 Academia Road, Sec. 2, Taipei 115, Taiwan \\ ${ }^{3}$ Department of Sociology, National Taiwan University,1 Roosevelt Road, Sec. 4, Taipei 106, Taiwan \\ ${ }^{4}$ National Center for Research on Earthquake Engineering, 200 Xinhai Road, Sec. 3, Taipei 106, Taiwan \\ ${ }^{5}$ Earth Observatory of Singapore, Nanyang Technological University N2-01A-14, 50 Nanyang Avenue, 639798, Singapore \\ ${ }^{6}$ Institute of Sociology, Academia Sinica, 128 Academia Road, Sec. 2, Taipei 115, Taiwan
}

Correspondence to: Y.-C. Chang (yichunchang.tw@gmail.com)

Received: 27 November 2014 - Published in Nat. Hazards Earth Syst. Sci. Discuss.: 27 January 2015

Revised: 31 August 2015 - Accepted: 31 August 2015 - Published: 1 October 2015

\begin{abstract}
While disaster studies researchers usually view risk as a function of hazard, exposure, and vulnerability, few studies have systematically examined the relationships among the various physical and socioeconomic determinants underlying disasters, and fewer have done so through seismic risk analysis. In the context of the 1999 Chi-Chi earthquake in Taiwan, this study constructs three statistical models to test different determinants that affect disaster fatality at the village level, including seismic hazard, exposure of population and fragile buildings, and demographic and socioeconomic vulnerability. The Poisson regression model is used to estimate the impact of these factors on fatalities. Research results indicate that although all of the determinants have an impact on seismic fatality, some indicators of vulnerability, such as gender ratio, percentages of young and aged population, income and its standard deviation, are the important determinants deteriorating seismic risk. These findings have strong social implications for policy interventions to mitigate such disasters.
\end{abstract}

\section{Introduction}

Disaster studies is a growing field which integrates the natural and social sciences (Mileti, 1999; Tierney, 2007). Over the past few decades, our understanding of natural hazards has grown significantly (IRDR, 2013; ICSU, 2010). And scientists can now more accurately characterize the possible magnitude of a given hazard, estimate the possibility of its occurrence and evaluate potential exposure areas. However, far less is known about the interaction of natural hazards and human-made factors in terms of disaster losses (ISSC, 2013), and little empirical work of effective interdisciplinary collaboration has been done to examine the coupling of natural and social determinants underlying disaster impacts (McBean, 2012; ICSU, 2010).

Human action has long been understood to have an impact on disaster outcomes, and over the past few decades a rich literature has firmly recognized disaster as a process of social construction (Bankoff et al., 2004; Clark and Munn, 1986; Kasperson and Kasperson, 2005). Over time, the notion of vulnerability has gained increased emphasis in disaster risk studies, promoted by Intergovernmental Panel on Climate Change (IPCC), United Nations Office for Disaster Risk Reduction (UNISDR) and many other initiatives since 2000 (McCarthy et al., 2001; Cardona et al., 2012). Its application in seismic studies is also extensive, ranging from a more limited interpretation on susceptibility assessments of the built environment (Calvi et al., 2006; Tyagunov et al., 2006) to a more complex modeling for risk assessment (Cardona et al., 2008). However, despite a few cross-national studies (Keefer et al., 2011; Lin, 2015) which do not exactly control for the magnitude of earthquakes, few empirical investigations have been made to holistically examine the social and physical determinants underpinning seismic risk through an integrative risk definition. This study presents an 
attempt to integrate research from seismology, seismic engineering, geography and sociology to clarify the multidimensional driving forces underlying seismic risk.

This study takes an interdisciplinary and holistic perspective in investigating the physical and social determinants which lead to high seismic fatality risk. The risk assessment model proposed by IPCC $(2012,2014)$ is applied to the 1999 Chi-Chi earthquake (Taiwan) by integrating seismic, building, demographic and socioeconomic data sets at village level. The Poisson regression model is used to estimate the effect of natural hazards and social factors on fatalities. Statistical results show that seismic hazard in the form of ground shaking and ground failure, exposure measured by population and fragile buildings, and vulnerability measured by gender ratio, percentages of young and aged population, income and its standard deviation (presenting income inequality) are all critical determinants affecting disaster fatality in the examined villages. This interdisciplinary collaboration effectively sheds light on the role played by natural hazards and social factors in seismic risk.

\section{Progression of seismic risk studies}

The development of modern risk analysis and assessment is closely linked to the establishment of scientific methodologies used to identify causal links between adverse effects and different types of hazardous events, and mathematical theories of probability (Cardona et al., 2012; Covello and Mumpower, 1985). However the terminology has not been defined uniformly across the various disciplines involved. In the natural sciences, risk is defined as the probability of an event occurring multiplied by its consequences (Thywissen, 2006). However, in the geosciences and multidisciplinary sciences, risk refers to the degree of potential loss due to exposure to hazards and the degree of social vulnerability (Rashed and Weeks, 2003). In the early 1980s, a report of the United Nations Disaster Relief Organization treated risk as a function of hazard, exposure and vulnerability (UNDRO, 1980). But this conceptualization received little attention at the time because the concept of vulnerability was not adequately explored by the academic community until quite recently (Adger, 2006; Timmerman, 1981; Watts and Bohle, 1993), resulting in the broad application of risk definitions across disciplines including IPCC and the disaster research community (IPCC, 2012, 2014).

Prior to the establishment of a consistent literature on social vulnerability index (Cutter, 1996, 2003), conventional perspectives for analyzing seismic risk include the seismic hazard perspective and the population-building exposure perspective. The seismic hazard perspective addresses the geological and physical characteristics of seismology (Wu et al., 2004). The population-building exposure perspective looks at the specific mechanisms surrounding building structures and seismic hazards that underpin the causality of mortality (Scawthorn et al., 2006; Yeh et al., 2006). But these two approaches present a limited capacity to explain mortality. For example, Wu et al. $(2002,2004)$ investigated the relationship between damage rate (fatality and house collapse rates) and seismic magnitude at the township scale, and found no obvious correlation among fatality, house collapse, and Peak Ground Acceleration (PGA) or Peak Ground Velocity (PGV). As a result, vulnerability studies were introduced to investigate socioeconomic determinants in earthquake fatalities. The three approaches are briefly reviewed below.

\subsection{Seismic hazard perspective}

The seismic hazard perspective usually considers two crucial physical determinants to measure the hazard ground shaking and ground failure (Yeh et al., 2006). Ground shaking is the direct result of wave propagation during an earthquake (Lay and Wallace, 1995). Increased ground shaking is expected in the region near the epicenter (Wu et al., 2002), in areas characterized by soft soil or in a basin (Wu et al., 2004). Accompanying widespread ground shaking, surface ruptures could damage structures due to ground failure, i.e., fault rupturing to the surface, soil liquefaction, and the associated ground settlement and lateral spreading. For example, during the 1999 Chi-Chi earthquake, a surface rupture with displacement exceeding $8 \mathrm{~m}$ along the northern part of the Chelungpu Fault caused severe damage to buildings and infrastructure, including dams and bridges (Chen et al., 2001; Ma et al., 1999).

\subsection{Population-building exposure perspective}

This approach is widely used in seismic risk assessments. It studies the specific mechanism surrounding seismic hazards and building structures that determine the causality, given the concept that earthquake-induced mortality is the complex outcome of a natural disaster combined with the failure of man-made environments. In the past decades, geographical information system-based software and methodologies have been developed and integrated in the analysis for earthquake loss estimation; some examples include the HAZUS Earthquake Model and the Taiwan Earthquake Loss Estimation System (TELES). The HAZUS Earthquake Model (Scawthorn et al., 2006) was developed by U.S. Federal Emergency Management Agency (FEMA, 2010), while TELES (Yeh et al., 2006) was developed by the National Center for Research on Earthquake Engineering, Taiwan. Both models treat seismic risk as the occurrence (probability) of a seismic event, exposure of people and properties (usually buildings) to the event, and the consequences of that exposure.

In this approach, it is crucial to establish estimates of building damage. Buildings are first categorized to account for various structural types (model building type), seismic performance levels (coded seismic design level) and usage (specific occupancy class). Building fragility models are then 
developed according to the structural characteristics of any combination of model building type and seismic design level, and also according to the damage evidence collected in the field (Yeh et al., 2006). The severity of building damage can therefore be estimated by the extent of ground shaking and ground failure of a seismic event. The casualty and injury rates can be further calculated by using the empirical evidence of casualty and injury rates of certain damaged buildings, and also based on the model simulation of the population distribution in the buildings devoted to various usages (i.e., commercial buildings, schools, or residential buildings) and at different times (i.e., population distribution at $8 \mathrm{am}$ and $8 \mathrm{pm}$ are likely to have very different patterns).

The above presents an important progression of seismic risk studies from a hazard-oriented perspective towards one which considers how the built-up environment and population distribution mediate the impact of a physical event. The introduction of cross-disciplinary approaches has stimulated the integration of a vulnerability-oriented perspective in the analysis.

\subsection{Vulnerability perspective}

Vulnerability is widely referred to as social processes that shape human and economic losses in disasters (Blaikie et al., 1994; Cardona et al., 2012; Aysan, 1993). This perspective emphasizes that disasters are a social construction and an outcome of human activity that transforms natural hazard into disaster risk (IPCC, 2012). The most significant work on social vulnerability with respect to risk was carried out by geographer Cutter and the colleagues who used a hazards-of-place model and county-level socioeconomic and demographic data to construct an index of social vulnerability (SoVI) for the United States (Cutter et al., 2003). In the model, risk is interpreted as an object measure of the likelihood of a hazard event that interacts with mitigation to produce hazard potential. The hazard potential is either moderated or enhanced by a geographic filter (site or situation of the place) as well as the social fabric of the place (Cutter et al., 2003). This paper also provided a wide review of the major vulnerability factors that are generally recognized in the vulnerability literature. These factors include demographic characteristics (Cutter, 1996), poverty and income inequality (Anbarci et al., 2005), inappropriate urban development (Pelling, 2003), and the mechanisms involved in social networks and social support systems (Klinenberg, 2002). Besides the SoVI, a wide array of vulnerability assessment methodologies are developed including community vulnerability assessment tool (CVAT) proposed by the U.S. National Oceanic and Atmospheric Administration (NOAA, 2003). Most of these assessment tools are performed through a geographical information system, and are served as a planning and decision support system for disaster management.

In the social science literature of disaster, economic development may be the most critical determinant shaping vulner- ability (Cutter, 1996). From the rational choice perspective, Kahn (2005) argued that politicians and citizens in developed countries have greater economic motivation to invest in disaster mitigation as an attempt to save lives and property. By contrast, leaders in developing countries tend to allocate resources to other political and development goals rather than for disaster preparedness (Keefer et al., 2011). This implies that countries, communities or households with higher income levels are more likely to invest in disaster mitigation.

Economic inequality is another frequently mentioned factor that determines vulnerability. Using country-level data, Anbarci et al. (2005) argue that increased income inequality is negatively correlated with the likelihood of various income groups to agree on the distribution of the burden of preparedness, causing the rich to self-insure against disasters, while the poor are excluded. While some studies suggest that the local community is one of the most crucial units for promoting disaster resilience or the establishment of social support systems to mitigate vulnerability (Aldrich and Sawada, 2015), most statistical analysis is still performed at the national, sub-national or municipal levels due to the difficulty of acquiring sufficient income distribution data at the community level.

The role of demography in disaster risk is also widely discussed. A great deal of research has revealed that the young and elderly are more likely to be affected by hazards (Donner and Rodríguez, 2008). For example, in Japan's 1995 Hanshin earthquake and 2011 Tōhoku earthquake and tsunami, the elderly accounted for approximately 60 and $65 \%$ of all victims respectively, while only accounting for 11 and $25 \%$ of the national population at the time of those two disasters (Khazai et al., 2011). In contrast, Haiti's 2011 earthquake resulted in a relatively higher death toll among children as a result of the country's high poverty, high fertility rate, and younger demographics (CDC, 2011). These demographic vulnerabilities can be explained by a lack of disaster safety knowledge or reaction capacity among children and the physical limitations of the elderly, leaving them unable to avoid the negative impacts of hazards.

Gender is another important determinant of vulnerability. A substantive literature has demonstrated that women are more likely to fall victim to natural disaster than men because women generally tend to have lower incomes, are more politically and socially marginalized, or are more likely to live alone (Fothergill, 1996). In addition, social expectations that women will take responsibility for caring for children and the elderly increases women's vulnerability (Enarson, 1998).

The factors mentioned above comprise a complicated fabric of social processes that are likely to influence fatality outcomes when a disaster occurs. However, barriers between academic disciplines have hindered the integration of these three perspectives of risk analysis, with each presenting a distinct view within which research specificity is bounded by the various disciplines. This study is an attempt to merge these perspectives as described below. 


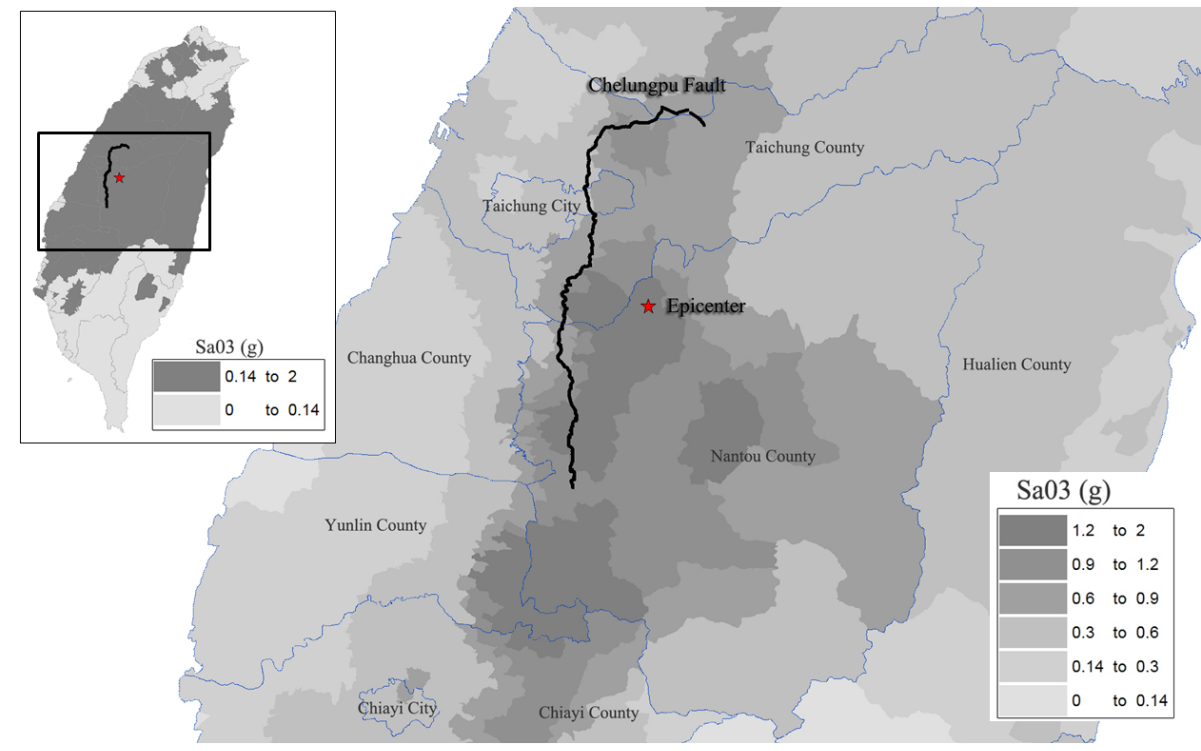

Figure 1. Epicenter, Chelungpu Fault and distribution of seismic intensity of the 1999 Chi-Chi earthquake, Taiwan. Note: Sa03 stands for spectral acceleration at $0.3 \mathrm{~s}$. Sa03 greater than $0.14 \mathrm{~g}$ is generally considered the threshold that would result in destructive damage and loss.

\subsection{Data and method}

\subsection{Hypothesis and model definition}

The risk formula used in this study is adopted from UNDRO (1980) and IPCC (2012) that defines risk as a function of the compounding effects of hazard, exposure and vulnerability as follows:

$$
\begin{gathered}
\text { Seismic Risk }=\text { Seismic Hazard } \times \text { Exposure } \times \text { Vulnerability } \\
\left.\begin{array}{c}
\begin{array}{c}
\text { Seismic Risk } \\
\text { (fatality) }
\end{array} \\
\text { Seismic Hazard } \\
\text { ground shaking level } \\
\text { surface rupture }
\end{array}\right) \times\left(\begin{array}{c}
\text { Exposure } \\
\text { population } \\
\text { fragile building }
\end{array}\right) \\
\times\left(\begin{array}{c}
\text { Vulnerability } \\
\text { demographic traits } \\
\text { socioeconomic traits }
\end{array}\right)
\end{gathered}
$$

In this study, the dependent variable, seismic risk, is defined as the total number of fatalities induced by an earthquake. The ground shaking level of the earthquake and surface rupture are taken into account as the essential factors for seismic hazard. Exposure is defined as the total population exposed to the seismic hazard and fragile buildings. This populationbuilding exposure perspective conceptually views buildings as having an important impact on the degree to which the population is exposed to the seismic hazard. In other words, persons situated in fragile buildings with low seismic resistance would suffer from a higher degree of exposure from the doubling effect of the initial seismic hazard and the potential collapse of buildings. Following this concept, we thus define the exposure dimension as the exposure of population and fragile buildings to the hazard under the recognition that higher density of population and fragile building would increase the effect of exposure.
Vulnerability is defined as the demographic and socioeconomic factors that are likely to attenuate or aggravate the degree of fatality and injury of the population exposed to an earthquake. This study thus hypothesizes that seismic risk, denoted as fatality, is the combined result of the physical conditions of the seismic hazard, population-building exposure, and vulnerability. The hypothesis, along with the relationships among these factors, is thus examined in the following section using multiple data sets and regressions.

\section{Empirical case: Taiwan's Chi-Chi Earthquake}

\subsection{Background}

The Chi-Chi Earthquake struck at $01: 47 \mathrm{GMT}+8$ on 21 September 1999 and proved to be the largest and most devastating in Taiwan in decades. It took place in central Taiwan along a $90 \mathrm{~km}$ rupture in the Chelungpu Fault (Fig. 1). The $M_{\mathrm{L}} 7.3\left(M_{\mathrm{W}} 7.6\right)$ main shock and the following aftershocks killed 2444 people (included 29 missing) and injured more than 11000 , mostly due to building damage or collapse (Uzarski et al., 2001). According to local governmental statistics, mortality was concentrated in Taichung County (1138 fatalities) and Nantou county (928), which are relatively rural areas. During the earthquake, the Central Weather Bureau's (CWB) Taiwan Strong Motion Instrumentation Program (TSMIP) monitored around 650 free-field digital accelerograph stations, recording a wealth of digital ground motion data. The data, as compiled by Lee and Shin (2001) are used here to verify the proposed risk analysis approach. 
Table 1. Descriptive statistics of selected variables.

\begin{tabular}{|c|c|c|c|}
\hline$N=4502$ & Mean & SD & Min.-Maximum \\
\hline \multicolumn{4}{|l|}{ Dependent variable } \\
\hline$\overline{\text { Fatalities }}$ & 0.52 & 3.78 & $0-87$ \\
\hline \multicolumn{4}{|l|}{ Seismic hazard variables } \\
\hline$\overline{\mathrm{Sa03}(g)}$ & 0.36 & 0.27 & $0.14-1.86$ \\
\hline Fault-influenced villages (dummy) & 0.03 & 0.17 & $0-1$ \\
\hline \multicolumn{4}{|l|}{ Exposure and building fragility variables } \\
\hline$\overline{\text { Population }(10000 \text { people })^{\mathrm{a}}}$ & 11.00 & 11.63 & $0.33-52.39$ \\
\hline Percentage of low seismic capacity buildings & 0.37 & 0.21 & $0-1$ \\
\hline \multicolumn{4}{|l|}{ Vulnerability variables } \\
\hline$\overline{\text { Sex ratio }^{\mathrm{a}}}$ & 1.08 & 0.07 & $0.94-1.35$ \\
\hline Percentage of population under age $14^{\mathrm{a}}$ & 0.21 & 0.03 & $0.12-0.28$ \\
\hline Percentage of population over age $65^{\mathrm{a}}$ & 0.09 & 0.03 & $0.04-0.19$ \\
\hline ln (Median of household income before tax) & 1.63 & 0.17 & $0.81-2.66$ \\
\hline Standard deviation of household income before tax & 6.68 & 8.82 & $1.82-237.35$ \\
\hline
\end{tabular}

Note: $N$ refers to population size. In this study, only 4502 out of 7353 villages in Taiwan with Sa03 greater than or equal to $0.14 \mathrm{~g}$ in Chi-Chi earthquake are analyzed.

Most of the statistics are computed at the village scale, except those marked with ${ }^{\text {a }}$ that are calculated through township level aggregative data.

Table 2. Simple correlations among independent variables.

\begin{tabular}{|c|c|c|c|c|c|c|c|c|c|c|}
\hline & & (1) & (2) & (3) & (4) & $(5)$ & (6) & (7) & (8) & (9) \\
\hline (1) & $\mathrm{Sa} 03(g)$ & 1 & & & & & & & & \\
\hline (2) & Fault-influenced villages & $0.36^{\mathrm{a}}$ & 1 & & & & & & & \\
\hline (3) & Percentage of low seismic capacity buildings & $-0.21^{\mathrm{a}}$ & 0.02 & 1 & & & & & & \\
\hline (4) & Population (10000 people) & $-0.26^{\mathrm{a}}$ & -0.03 & $0.18^{\mathrm{a}}$ & 1 & & & & & \\
\hline (5) & Sex ratio & $0.18^{\mathrm{a}}$ & -0.02 & $-0.09^{\mathrm{a}}$ & $-0.63^{\mathrm{a}}$ & 1 & & & & \\
\hline (6) & Percentage of population under age 14 & -0.02 & $0.05^{\mathrm{a}}$ & $0.20^{\mathrm{a}}$ & $0.23^{\mathrm{a}}$ & $-0.51^{\mathrm{a}}$ & 1 & & & \\
\hline (7) & Percentage of population over age 65 & $0.16^{\mathrm{a}}$ & $-0.03^{\mathrm{a}}$ & $-0.24^{\mathrm{a}}$ & $-0.59^{\mathrm{a}}$ & $0.70^{\mathrm{a}}$ & $-0.82^{\mathrm{a}}$ & 1 & & \\
\hline (8) & $\ln ($ Median of HIT) & $-0.14^{\mathrm{a}}$ & -0.03 & 0.02 & $0.48^{\mathrm{a}}$ & $-0.62^{\mathrm{a}}$ & $0.25^{\mathrm{a}}$ & $-0.36^{\mathrm{a}}$ & 1 & \\
\hline (9) & SD of HIT & $-0.07^{\mathrm{a}}$ & -0.02 & 0.01 & $0.21^{\mathrm{a}}$ & $-0.29^{\mathrm{a}}$ & $0.05^{\mathrm{a}}$ & $-0.11^{\mathrm{a}}$ & $0.42^{\mathrm{a}}$ & 1 \\
\hline
\end{tabular}

Note: ${ }^{\mathrm{a}} p<0.05$, for the check of multi-collinearity among independent variables.

\subsection{Data and method}

In order to test our hypothesis, we collected data from different sources, including strong motion records from the Central Weather Bureau, building (tax) data from the Ministry of Finance, population data from the Ministry of the Interior, socioeconomic data from the Ministry of Finance, and fatality data from Pai (2006). The analytical unit of this study is the village, which constitutes the smallest administrative unit in Taiwan. However, due to the difficulty of collecting sufficient official demographic data at the village scale, the demographic characteristics are analyzed at the township level. Table 1 summarizes descriptive statistics for the selected variables in which most of the variables are computed at village scale except those pertinent to demographics that are computed at township level. The simple correlations among the independent variables are provided in Table 2.

The dependent variable in this study is the death toll in each village (Kahn, 2005; Keefer et al., 2011). This is a count variable, thus the Poisson regression model is applied to test the hypothesis. For a non-negative counted integer, the simplest and most popular applied distribution is the Poisson (Agresti 2002), the probability mass function of which is

$\operatorname{Pr}(y)=\frac{e^{-\mu} \mu^{y}}{y !}, y=0,1,2, \ldots$

This satisfies $E(Y)=\operatorname{var}(Y)=\mu$. The Poisson distribution is used to account for events that occur randomly over time or space, when the outcomes in disjointed periods or regions are independent. If $\boldsymbol{x}_{j}$ is a vector of $p$ independent variables, and the Poisson probability function can be presented as $E(Y \mid x)=e^{\sum_{j=0}^{p} \beta_{j} X_{j}}$. The model takes the $\log$ arithmic form $\log E(Y \mid x)=\sum_{j=0}^{p} \beta_{j} X_{j}$, which can be estimated by a maximum likelihood method of the General Linear Model (GLM). In our original models, the positive or negative coefficient $\beta_{j}$ can be simply understood as the increase or decrease $\log E(Y \mid x)$ of death $(Y)$ caused by the 
Table 3. Statistical models to estimate seismic fatalities in the 1999 Chi-Chi earthquake: the Poisson regression.

\begin{tabular}{|c|c|c|c|}
\hline & Model 1 & Model 2 & Model 3 \\
\hline \multicolumn{4}{|l|}{ Seismic Hazard Variables } \\
\hline $\mathrm{Sa} 03(g)$ & $\begin{array}{l}16.91^{\mathrm{b}} \\
(0.86)\end{array}$ & $\begin{array}{l}25.87^{\mathrm{b}} \\
(1.49)\end{array}$ & $\begin{array}{l}27.39^{b} \\
(1.63)\end{array}$ \\
\hline Fault-influenced & $\begin{array}{l}6.33^{\mathrm{b}} \\
(0.29)\end{array}$ & $\begin{array}{l}5.21^{\mathrm{b}} \\
(0.24)\end{array}$ & $\begin{array}{l}4.92^{\mathrm{b}} \\
(0.23)\end{array}$ \\
\hline \multicolumn{4}{|l|}{ Exposure and Building Fragility Variables } \\
\hline Population (10 000 people) & & $\begin{array}{l}1.02^{\mathrm{b}} \\
(0.003)\end{array}$ & $\begin{array}{l}1.01^{\mathrm{b}} \\
(0.004)\end{array}$ \\
\hline Percentage of low seismic capacity buildings & & $\begin{array}{l}5.88^{\mathrm{b}} \\
(0.68)\end{array}$ & $\begin{array}{l}6.17^{\mathrm{b}} \\
(0.73)\end{array}$ \\
\hline \multicolumn{4}{|l|}{ Vulnerability Variables } \\
\hline Sex ratio & & & $\begin{array}{l}0.08^{\mathrm{b}} \\
(0.05)\end{array}$ \\
\hline Percentage of population under age 14 & & & $\begin{array}{l}284.18^{\mathrm{a}} \\
(634.01)\end{array}$ \\
\hline Percentage of population over age 65 & & & $\begin{array}{l}124.18 \\
(315.56)\end{array}$ \\
\hline Ln (median household income before tax) & & & $\begin{array}{l}0.53^{\mathrm{b}} \\
(0.10)\end{array}$ \\
\hline SD of household income before tax & & & $\begin{array}{l}1.01^{\mathrm{b}} \\
(0.002)\end{array}$ \\
\hline Intercept & $\begin{array}{l}0.07^{\mathrm{b}} \\
(0.003)\end{array}$ & $\begin{array}{l}0.02^{\mathrm{b}} \\
(0.002)\end{array}$ & $\begin{array}{l}0.19 \\
(0.19)\end{array}$ \\
\hline$N$ & 4502 & 4502 & 4502 \\
\hline Log lik. & -5204.31 & -5051.55 & -5026.07 \\
\hline Pseudo R-square & 0.393 & 0.411 & 0.414 \\
\hline
\end{tabular}

Standard errors in parentheses, ${ }^{\mathrm{a}} p<0.05,{ }^{\mathrm{b}} p<0.001$.

Chi-Chi earthquake when the independent variable $\boldsymbol{x}_{j}$ increases by one unit. The statistical result can be transferred back to an exponential relationship, which is a positive correlation between $X_{j}$ and the predicted incidence rate ratios $\mathrm{E}(Y \mid x)$, as shown in Table 3.

The independent variables include measurements from the three perspectives of seismic risk. The seismic hazard perspective comprises two variables: seismic intensity and surface rupture. This study uses spectral acceleration to measure seismic intensity as it is apparently more representative than PGA and PGV from the perspective of seismic risk (Wu et al., 2002, 2004). In seismology engineering, spectral acceleration is the response of a damped structure (i.e., a building) in terms of acceleration under strong motion excitation, and is modeled as a particle mass on a massless vertical rod having the same natural period of vibration as the type of building in question. It can be calculated from the time history of a ground acceleration record given the period of the building (typically with a $5 \%$ damping ratio). Here, the seismic records of the spectral acceleration at $0.3 \mathrm{~s}$ (denoted as Sa03) are used (Fig. 1). Because the heavily affected areas are mostly suburban and rural areas around the Chelungpu Fault, the majority of buildings are low rise (1-3 stories) with a natural period of vibration of around $0.3 \mathrm{~s}$. According to the seismic design code, $\mathrm{Sa} 03$ of $0.14 \mathrm{~g}$ is approximately of peak ground acceleration around $0.056 \mathrm{~g}$. It is classified as Seismic Intensity IV by the Central Weather Bureau, which suggests

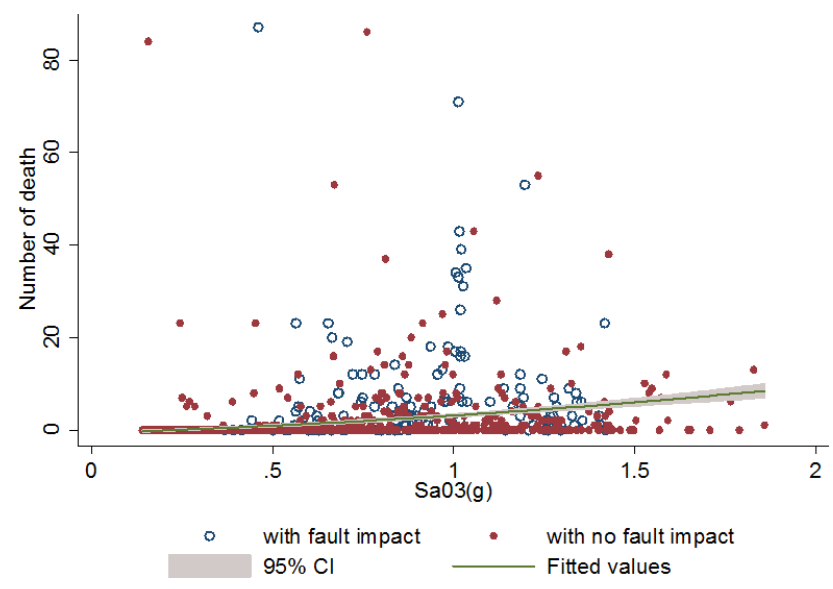

Figure 2. $\mathrm{Sa} 03$ and fatalities at the village level in the $1999 \mathrm{Chi}-\mathrm{Chi}$ earthquake. Notes: Blue hollow spot refers to the villages with fault impact; red spot refers to those without fault impact. The fitted line refers to the exponential relationship between $\mathrm{Sa} 03(\mathrm{~g})$ and number of deaths.

no damage occurs. This study thus considers 4502 villages with $\mathrm{Sa} 03$ greater than or equal to $0.14 g$ during the earthquake. As shown in Fig. 2, in the Chi-Chi earthquake, the records of seismic intensity correlated to fatalities, but alone can hardly explain the great variety of fatalities. In terms of fault crossing, the surface rupture of the Chelungpu Fault surveyed by Chen et al. (2001) is overlaid to identify the trail and distribution of the fault rupture. A village is coded 1 if this village is located on the fault (that is, blue hollow spots on Fig. 2), whereas 0 if it is not (red spots on Fig. 2).

The population-building exposure perspective includes two variables which aim to measure the extent to which population and fragile buildings in each village are exposed to the hazard. The total township population data are applied to estimate population exposure. Building fragility is measured as the percentage of buildings with low seismic capacity. A village with higher ratio of low seismic capacity buildings indicates a higher degree of building fragility. The seismic zonation and design force level can be classified based on the history of seismic design codes for the buildings. Similar to the HAZUS methodology (Scawthorn et al., 2006), buildings are categorized into four seismic design levels (high, moderate, low and pre-code) according to the construction year and location. In this study, pre-code and low-code buildings are viewed as having low seismic capacity, and the floor area-based percentage of low seismic capacity buildings of all buildings in each village in the year 2000 is calculated using building tax data. Generally, the average percentage is $37 \%$ among the studied villages (Table 1).

Several components of the vulnerability perspective are considered. The overall sex ratio (i.e., male population divided by female) is a measurement of the vulnerability of females within the population. For this study, the overall sex ratio is 1.08 on average, meaning that males outnumber fe- 
males in the studied townships. The population dependency factor calculates the percentage of the population under the age of 14 and over the age of 65 . A larger dependent population, either young or aged, indicates a higher degree of demographic vulnerability. Finally, for the socioeconomic component of vulnerability, the median and standard deviation of household income before tax are used to assess economic development and income inequality (Kahn, 2005; Kellenberg and Mobarak, 2008). This operation is widely applied to represent the conception of socioeconomic vulnerability, using the logarithm of median household income before tax, which indicates the economic development of each village, while the standard deviation of household income before tax reflects the extent of income inequality within a given village. Overall, in the study, the standard deviation of annual household income before tax ranges from TWD 182000 to TWD 2370000 (approx., USD 6000 to USD 62 000) (Table 1).

We apply the STATA to calculate the coefficients of the Poisson models. The program of the baseline model is "poisson ..., irr". The command "irr" reports estimated coefficients transformed to incidence-rate ratios (or interpreted as incidence density ratios), that is, exponential $\beta_{j}$. For those who are interested in the combined data set, please contact us by email.

\section{Results}

Table 3 summarizes the results of the Poisson regression analysis for testing the seismic risk hypothesis in the Chi-Chi earthquake. The coefficient has been transformed back to the positive exponential relationship between each independent variable and the predicted incidence rate ratio. According to the Poisson function $e^{\beta_{j} X_{j}}$, if the coefficient equals 1 , the variable is irrelevant to the incidence rate ratio on average. If the coefficient is greater than 1, ceteris paribus, each unit of the variable has an exponential impact on the incidence rate ratio. However, ceteris paribus, if the coefficient is smaller than 1 , each unit of the variable reduces the incidence rate ratio in an exponential proportion.

We estimated three nested regression models to illustrate the impact of the variables on the death toll from the three perspectives, added one perspective by another, respectively. Model 1 estimates the impact of the seismic hazard, including $\mathrm{Sa} 03$ and surface-rupture, on the death toll in each village. The result shows that $\mathrm{Sa} 03$ and positioning on the fault are positively correlated to the number of fatalities. The Pseudo R-square, an indicator of goodness of fit, shows that the model can explain around $39.3 \%$ of the variations of the dependent variable. By adding the variables of population size and building fragility, Model 2 shows significant coefficients for the variables to improve the model's robustness, i.e., the significance of the seismic hazard variable also increases. The Pseudo R-square shows that the model can explain around $41.1 \%$ of the fatality's variations. Based on Model 2, Model 3 further integrates vulnerability variables.

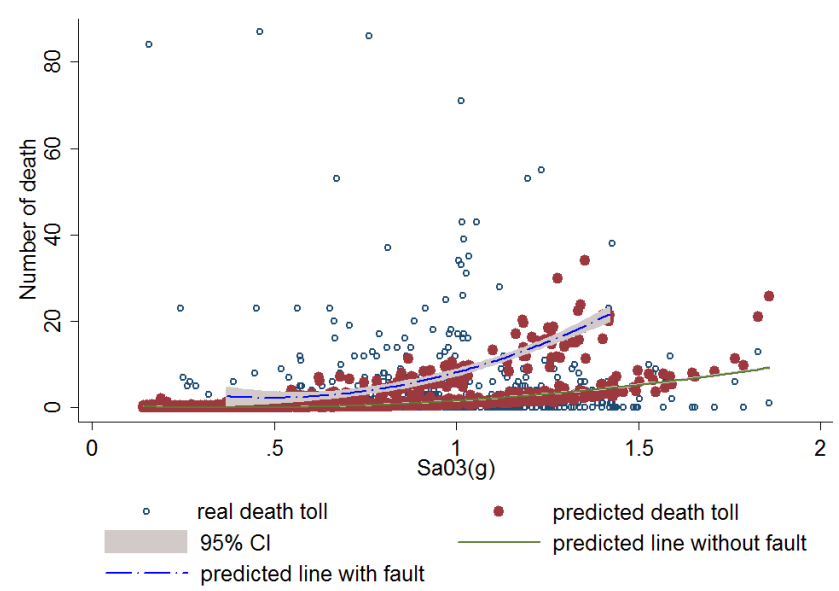

Figure 3. Causality among Sa03, Chelungpu fault and fatality in the 1999 Chi-Chi Earthquake. Note: red spot refers to the estimated fatalities (Model 3). Two curves refer to the fitted exponential relationship between $\mathrm{Sa03}(\mathrm{g})$ and the estimated number of deaths with fault impact (blue dashed curve) and without fault (brown curve). Blue hollow spot refers to the real death toll, around which $41.4 \%$ can be explained by the model.

Model 3 is our complete model showing that most of the variables from the three perspectives significantly affect seismic fatality. However, compared to Model 2, the pseudo R-square of Model 3 only improves $0.3 \%$ with varying contribution from each of the variables of the three perspectives. It can be interpreted that the complete model can predict 41.4 fatalities in the village where the real observation of fatality is 100 , according to the limited information.

Based on the result of Model 3, the seismic hazard is shown to be the most important factor in determining fatalities in the Chi-Chi earthquake. One unit of $\mathrm{g}$ increased in $\mathrm{Sa} 03$ could result in a 27.39 -fold increase in fatalities in a village (mean $=0.52$ ), ceteris paribus. Having the fault cross the village resulted in a 4.92-fold increase. Because the seismic intensity is correlated to proximity to the fault (correlation $=0.36$, please see Table 2), the interaction of the two variables is the major determinant of the fatality rate. Figure 3 illustrates the exponential relationships between the seismic hazard variables and the predicted death toll (red spots), which explains $41.4 \%$ of the real observation (blue hollow spots). The result can be presented as the predicted death toll concentrated on two curves, the lower exponential curve without fault, and the 4.92-fold increased exponential curve of the fault-influenced villages, as the seismic intensity $\mathrm{Sa} 03$ increased.

The result of Model 3 also demonstrates a profound association between population-building exposure and fatalities. Each increase of 10000 residents in a township could result in a one percent increase in fatalities, while increasing the ratio of low seismic capacity buildings from 0 to $100 \%$ results in a 6.17-fold increase in fatalities. 
Finally the model shows that, although the impact of vulnerability may not be as significant as seismic hazard, it does contribute to earthquake fatalities. In our data set, the sex ratio falls in a range of $0.94-1.35$. The coefficient implies that each $10 \%$ increase in a village's sex ratio can reduce fatalities by $9.2 \%$. Although the coefficient for the percentage of population under age 14 rises to 284.18 , its range is within $0.12-0.28$ in the data set. That is to say, if the percentage increases from 0.12 to 0.22 , it could lead to a 28.4 -fold increase in fatalities. The coefficient of the percentage of population over age 65 (124.18) is also large but not significant. The problem of non-significance, however, might be due to the multicollinearity between the percentages of young and aged populations (correlation $=-0.82$, see Table 2 ).

The standard of economic development, as measured by the logarithmic median household income before tax, effectively reduces the incidence of fatalities. For example, each unit increase of the variable, namely Log 1000 (Taiwanese dollars), from 1 to 2 could produce a $47 \%$ reduction in the death toll. In addition, there is a significant relationship between income inequality and fatalities. Each NTD 100000 increase to the standard deviation of household income before tax (maximum NTD 237 350) could double the number of fatalities. Even though the impact of the vulnerability variables is smaller than those of seismic hazard or population and building exposure (and are difficult to express quantitatively), most coefficients are significant and match hypothetical expectations.

As mentioned above, our final model can only explain $41.4 \%$ of the total observed fatalities, which means that $58.6 \%$ of fatalities can hardly be explained in the model. Although some interactions among variables may be considered, such as the possible relationships between exposure and vulnerability, most of the unexplained fatalities may result from omitted factors such as crime or some collective behavior in the reality. This reflects the necessity of more intensive investigation to be made on wider physical and social determinants shaping the earthquake fatality in the future study.

\section{Discussion and conclusions}

Integrating research from seismology, seismic engineering, geography and sociology, this study seeks to examine and verify multi-dimensional driving forces (i.e., the physical, demographic, and socioeconomic determinants along with building fragility) which underlie seismic risk using the integrated risk formula (IPCC, 2012, 2014). Concepts are carefully defined and measurements used in the models are selected based on a systematic literature review of the three perspectives, namely seismic hazard, population-building exposure, and vulnerability. The Poisson regression models were applied to the case of the 1999 Chi-Chi earthquake in Taiwan to verify determinants in seismic fatality risk.

Three statistical models, considering seismic hazard, population exposure, and building fragility, demographic and so- cioeconomic vulnerability, are built to test the varying determinants for seismic fatality in the Chi-Chi earthquake. Results indicate that all components have an explicit impact on the specific dimension for seismic fatality risk. Thus such risk is regarded as an interactive construction of natural phenomena and social modification (Mileti, 1999).

Our study finds that seismic risk is increased in areas characterized by more fragile buildings, densely settled populations, a higher percentage of disadvantaged populations (i.e., children, the elderly, and women), reduced economic development and increased income inequality. It is important to reiterate that buildings and social conditions are in place well before the occurrence of any disaster event, thus much of the potential could be managed or alleviated through proactive intervention or disaster mitigation policies to reduce building fragility and vulnerability (Kasperson and Berberian, 2011; Lin et al., 2011). Such policies could include efforts to promote effective land planning and building regulations, strengthen structural resilience, enhance social networks and welfare systems, and reduce socioeconomic inequality. These institutional arrangements are particularly important in communities which consistently face natural hazards.

This study demonstrates the advantage of adopting an interdisciplinary perspective for the social and physical determinants of seismic risk. Future studies should examine the impact of additional social determinants (e.g., crime, social capital, and health) on seismic or other hazard risks, and geographical information systems can be applied to analyze the socio-spatial effects of seismic risk variables. Understanding disaster risk as an interaction between natural and social factors allows the focus to shift from disaster response toward disaster prevention (Cardona et al., 2008, 2012). This implies that seismic risk could potentially be mitigated by an improved understanding of risk determinants along with improved institutional arrangements to reduce the risk.

Acknowledgements. The authors would like to thank G. Arun and another anonymous referee for their careful and positive reviews on the paper and the editor's great comments that have together substantially strengthened the paper.

Edited by: P. Reichenbach

Reviewed by: G. Arun and one anonymous referee

\section{References}

Adger, W. N.: Vulnerability, Global Environ. Chang., 16, 268-281, 2006.

Agresti, Al.: Categorical Data Analysis, second Edn., Wiley, New York, USA, 2002.

Aldrich, D. P. and Sawada, Y.: The physical and social determinants of mortality in the 3.11 tsunami, Soc. Sci. Med., 124, 66-75, 2015. 
Anbarci, N., Escaleras, M., and Register, C. A.: Earthquake fatalities: the interaction of nature and political economy, J. Public Econ., 89, 1907-1933, 2005.

Aysan, Y.: Vulnerability assessment, in: Natural Disasters: Protecting Vulnerable Communities, edited by: Merriman, P. A. and Browitt, C. W., IDNDR-Thomas Telford, London, UK, 1-14, 1993.

Bankoff, G., Frerks, G., and Hilhorst, D.: Mapping Vulnerability: Disasters, Development and People, Earthscan, Sterling, VA, USA, 2004.

Blaikie, P., Cannon, T., Davis, I., and Wisner, B.: At Risk: Natural Hazards, People's Vulnerability, and Disasters, Routledge, London, UK, 1994.

Calvi, G. M., Pinho, R., Magenes, G., Bommer, J. J., RestrepoVelez, L. F., and Crowley, H.: Development of seismic vulnerability assessment methodologies over the past 30 years, ISET J. Earthq. Technol., 43, 75-104, 2006.

Cardona, O. D., Ordaz, M. G., Yamin, L. E., Marulanda, M. C., and Barbat, A. H.: Earthquake loss assessment for integrated disaster risk management, J. Earthq. Eng., 12, 48-59, doi:10.1080/13632460802013495, 2008.

Cardona, O. D., van Aalst, M. K., Birkmann, J., Fordham, M., McGregor, G., Perez, R., Pulwarty, R. S., Schipper, E. L. F., and Sinh, B. T.: Determinants of risk: exposure and vulnerability, in: Managing the Risks of Extreme Events and Disasters to Advance Climate Change Adaptation. A Special Report of Working Groups I and II of the Intergovernmental Panel on Climate Change (IPCC), edited by: Field, C. B., Barros, V., Stocker, T. F., Qin, D., Dokken, D. J., Ebi, K. L., Mastrandrea, M. D., Mach, K. J., Plattner, G.-K., Allen, S. K., Tignor, M., and Midgley, P. M., Cambridge University Press, Cambridge, UK and New York, USA, 65-108, 2012.

CDC: Post-Earthquake Injuries Treated at a Field Hospital Haiti 2010, Morbidity and Mortality Weekly Report (MMWR) 59, Centers for Disease Control and Prevention (CDC), Atlanta, GA, USA, 1673-1677, available at: http://www.cdc.gov/ $\mathrm{mmwr} /$ preview/mmwrhtml/mm5951a1.htm (last access: 15 January 2015), 2011.

Chen, W. S., Huang, B. S., Chen, Y. G., Lee, Y. H., Yang, C. N., Lo, C. H., Chang, H. C., Sung, Q. C., Huang, N. W., Lin, C. C., Sung, S. H., and Lee, K. J.: Chi-Chi Earthquake: a case study on the role of thrust-ramp structures for generating earthquakes, B. Seismol. Soc. Am., 91, 986-994, 2001.

Clark, W. C. and Munn, R. E.: Sustainable Development of The Biosphere, Cambridge University Press, Cambridge, UK, 1986.

Covello, V. and Mumpower, J.: Risk analysis and risk management: an historical perspective, Risk Anal., 5, 103-120, 1985.

Cutter, S. L.: Vulnerability to environmental hazards, Prog. Hum. Geog., 20, 529-539, 1996.

Cutter, S. L., Boruff, B. J., and Shirley, W. L.: Social Vulnerability to Environmental Hazards, Soc. Sci. Quart., 84, 242-261, 2003.

Donner, W. and Rodríguez, H.: Population composition, migration, and inequality: the influence of demographic changes on disaster risk and vulnerability, Soc. Forces, 87, 1089-1114, 2008.

Enarson, E.: Through women's eyes: a gendered research agenda for disaster social science, Disasters, 22, 157-173, 1998.

FEMA: Hazus-MH Analysis Levels, Department of Homeland Security, Federal Emergency Agency, Washington DC, USA, 2010.
Fothergill, A.: Gender, risk, and disaster, International J. Mass Emerg. Disast., 14, 33-56, 1996.

ICSU: Earth System Science for Global Sustainability: the Grand Challenges, International Council for Science, Paris, France, 2010.

IPCC: Managing the Risks of Extreme Events and Disasters to Advance Climate Change Adaptation. A Special Report of Working Groups I and II of the Intergovernmental Panel on Climate Change, Cambridge University Press, Cambridge, UK, and New York, USA, 582, 2012.

IPCC: Climate Change 2014: Impacts, Adaptation, and Vulnerability. Working Group II Contribution to the IPCC 5th Assessment Report - Changes to the Underlying Scientific/Technical Assessment, Intergovernmental Panel on Climate Change, Cambridge University Press, Cambridge, UK and New York, NY, USA 2014.

IRDR: Integrated Research on Disaster Risk Strategic Plan 20132017, Integrated Research on Disaster Risk, Beijing, China, 2013.

ISSC: World Social Science Report: Changing Global Environments, International Social Sciences Council, Paris, France, 2013.

Kahn, M. E.: The death toll from natural disasters: the role of income, geography, and institutions, Rev. Econ. Stat., 87, 271-284, 2005.

Kasperson, J. X. and Kasperson, R. E.: The Social Contours of Risk: Risk Analysis, Corporations and the Globalization of Risk, Earthscan, London, UK, 2005.

Kasperson, R. E. and Berberian, M.: Integrating Science and Policy: Vulnerability and Resilience in Global Environmental Change, Earthscan, London, UK, 2011.

Keefer, P., Neumayer, E., and Plümper, T.: Earthquake propensity and the politics of mortality prevention, World Dev., 39, 1530 1541, 2011.

Kellenberg, D. K. and Mobarak, A. M.: Does rising income increase or decrease damage risk from natural disasters, J. Urban Econ., 63, 788-802, 2008.

Khazai, B., Daniell, J. E., and Wenzel, F.: The March 2011 Japan earthquake: analysis of losses, impacts, and implications for the understanding of risks posed by extreme events, Technikfolgenabschätzung - Theorie und Praxis, 20, 22-33, 2011.

Klinenberg, E.: Heat Wave: a Social Autopsy of Disaster in Chicago, University of Chicago Press, Chicago, USA, 2002.

Lay, T. and Wallace, T. C.: Modern Global Seismology, Academic Press, San Diego, CA, USA, 1995.

Lee, W. H. and Shin, T. T.: Strong-motion instrumentation and data, Earthq. Spectra Special Issue: Chi-Chi, Taiwan Earthquake, 17, 5-18, 2001.

Lin, T.-H.: Governing natural disasters: state capacity, democracy, and human vulnerability, Soc. Forces, 93, 1267-1300, 2015.

Lin, K. H., Tsai, H. M., and Chang, C. Y.: Science and vulnerability reduction in Taiwan - cross-scale communication, knowledge co-production, and boundary organization after the 1999 Chi-Chi Earthquake, in: Integrating Science and Policy: Vulnerability and Resilience in Global Environmental Change, edited by: Kasperson, R. E. and Berberian, M., Earthscan, London, USA, 233-268, 2011.

Ma, K. F., Lee, C. T., Tsai, Y. B., Shin, T. C., and Mori, J.: The ChiChi Taiwan earthquake: large surface displacements on an inland thrust fault, EOS, 80, 605-611, 1999. 
McBean, G. A.: Integrating disaster risk reduction towards sustainable development, Current Opinion in Environ. Sustain., 4, 122127, doi:10.1016/j.cosust.2012.01.002, 2012.

McCarthy, J. J., Canziani, O. F., Leary, N. A., Dokken, D. J., and White, K. S.: Climate Change 2001: Impacts, Adaptation and Vulnerability, Cambridge University Press, Cambridge, UK, 2001.

Mileti, D. S.: Disasters by Design: a Reassessment of Natural Hazards in the United States, Joseph Henry Press, Charleston, SC, USA, 1999.

NOAA: Risk and Vulnerability Assessment Tool, NOAA Coastal Services Center, Charleston, SC, USA, 2003.

Pai, C.-H.: A Method for Estimating the Distribution of Death Tolls Induced from the Disastrous Earthquake, National Central University Doctoral Dissertation, Zhongli, Taiwan, 1-183, 2006.

Pelling, M.: The Vulnerability of Cities: Natural Disasters and Social Resilience, Earthscan, London, UK, 2003.

Rashed, T. and Weeks, J. R.: Assessing vulnerability to earthquake hazards through spatial multicriteria analysis of urban areas, Int. J. Geogr. Inf. Sci., 17, 547-576, 2003.

Scawthorn, C., Flores, P., Blais, N., Seligson, H., Tate, E., Chang, S., Mifflin, E., Thomas, W., Murphy, J., Jones, C., and Lawrence, M.: HAZUS-MH flood loss estimation methodology. II. Damage and loss assessment, Nat. Hazards Rev., 7, 72-81, 2006.

Thywissen, K.: Core terminology of disaster risk reduction: a comparative glossary, in: Measuring Vulnerability to Natural Hazards, edited by: Birkmann, J., UNU Press, Tokyo, Japan, 448496, 2006.
Tierney, K. J.: From the margins to the mainstream? Disaster research at the crossroads, Annu. Rev. Sociol., 33, 503-525, 2007.

Timmerman, P.: Vulnerability, Resilience and the collapse of Society, University of Toronto, Institute of Environmental Studies, Research Paper, Toronto, Japan, 1981.

Tyagunov, S., Grünthal, G., Wahlström, R., Stempniewski, L., and Zschau, J.: Seismic risk mapping for Germany, Nat. Hazards Earth Syst. Sci., 6, 573-586, doi:10.5194/nhess-6-573-2006, 2006.

UNDRO: Natural Disasters and Vulnerability Analysis, UNDRO, Geneva, Switzerland, 1980.

Uzarski, J., O'Rourke, M., Abrahamson, N., and Amin, N. R.: Introduction to Chi-Chi, Taiwan earthquake, Earthq. Spectra Special Issue: Chi-Chi, Taiwan Earthquake, 17, 1-3, 2001.

Watts, M. J. and Bohle, H. G.: The space of vulnerability: the causal structure of hunger and famine, Prog. Hum. Geog., 17, 43-67, 1993.

Wu, Y.-M., Hsiao, N.-C., Teng, T.-L., and Shin, T.-C.: Near realtime seismic damage assessment of the rapid reorting system, TAO, 13, 313-324, 2002.

Wu, Y.-M., Hsiao, N.-C., and Teng, T.-L.: Relationships between strong ground motion peak values and seismic loss during the 1999 Chi-Chi Taiwan earthquake, Nat. Hazards, 32, 357-373, 2004.

Yeh, C. H., Loh, C. H., and Tsai, K. C.: Overview of Taiwan earthquake loss estimation system, Nat. Hazards, 37, 23-37, 2006. 